\title{
INFORMAÇÕES AMBIENTAIS APRESENTADAS NAS NOTAS EXPLICATIVAS DE COMPANHIAS PETROLEIRAS E SIDERÚRGICAS NO BRASIL
}

\author{
Sandro Vieira Soares \\ Mestrando em Contabilidade pela Universidade Federal de Santa Catarina - UFSC \\ sandrovieirasoares@hotmail.com \\ Gabriel Ribeiro Silva \\ Graduando em Ciências Contábeis pela Universidade Federal de Santa Catarina - UFSC \\ grs_90@yahoo.com.br \\ José Guilherme Soares \\ Graduando em Ciências Contábeis da Universidade Federal de Santa Catarina - UFSC \\ j.guilherme.soares@ hotmail.com \\ Bernadete Limongi \\ Pós Doutora pela University of Essex \\ Professora na Universidade Federal de Santa Catarina \\ bernadetelimongi@yahoo.com.br
}

\begin{abstract}
RESUMO
Este artigo tem por finalidade detectar informações acerca da Contabilidade Ambiental nas Notas Explicativas das Demonstrações Contábeis Obrigatórias dos anos de 2007, 2008 e 2009 das companhias abertas que atuam no ramo da siderurgia e exploração de petróleo. Esta pesquisa está classificada como descritiva quanto aos objetivos, documental e bibliográfica quanto aos procedimentos, e qualitativa quanto à abordagem dos dados. Os resultados apontam que as informações relacionadas ao meio ambiente encontradas nas notas explicativas das empresas tratam de ações judiciais decorrentes de danos causados ao meio ambiente, cálculos de provisões relacionadas a ações judiciais em andamento, seguros ambientais, Termos de Ajustamento de Conduta - TACs - firmados entre as empresas e o Ministério Público e, finalmente, cláusulas de contratos firmados pelas empresas que envolvem o meio ambiente. Verificou-se nesta pesquisa que as empresas não possuem um padrão de divulgação de informações ambientais nas notas explicativas. Cada uma adota um sistema conforme a necessidade de transmissão de informação aos interessados. A Petrobras foi a empresa que apresentou uma melhor evidenciação de informações ambientais nas Notas Explicativas, encontradas principalmente no capítulo "Segurança, saúde e meio ambiente".
\end{abstract}

Palavras-chave: Empresas siderúrgicas e petroleiras; Gestão ambiental; Notas explicativas.

\section{ENVIRONMENTAL INFORMATION PRESENTED IN THE NOTES OF OIL AND STEEL COMPANIES IN BRAZIL}

\begin{abstract}
This article aims at finding information about Environmental Accountancy in the Notes and Accounts of the "Obligatory Accounting Statements" in the years of 2007, 2008 and 2009 of the Public Capital Corporations that are active in the field of steel and petroleum exploration. This piece of research is classified as having descriptive objectives, documental and bibliographical procedures, and qualitative data. The results indicated that the information related to the environment, presented in the Notes and Accounts of the corporations, is connected to judicial proceedings in process, environmental insurance, Commitment of Procedure Changes signed by the corporations and the Department of Justice, and, finally, contract clauses that protect the environment signed by the corporations. This research revealed that companies do not have a standard of disclosure of environmental information in their notes and accounts. Each one developed their own system to transmit the information concerned. Petrobras was the company that made the best disclosure of environmental information in Notes, mainly found in the chapter "Safety, health and environment."
\end{abstract}

Key words: Environmental management; Oil companies; Notes to the accounts; Steel mills. 


\title{
1 INTRODUÇÃO
}

A Contabilidade Ambiental não é uma nova ciência, mas sim uma segmentação da Contabilidade tradicional, que, de acordo com Marion (2009), pode ser considerada como sistema de informação destinado a prover seus usuários de dados para ajudá-los a tomar decisão. Adaptando seu objetivo, pode-se definir que a finalidade da Contabilidade Ambiental é identificar, mensurar e esclarecer os eventos e transações econômico-financeiras que estejam relacionados com a proteção, a preservação e a recuperação ambiental (Ribeiro, 2010). Quanto aos ativos e passivos ambientais, ainda de acordo com Ribeiro (2010), os ativos devem ter controle, classificação e divulgação destacados nos grupos do Ativo e os passivos ambientais devem ser informados em subgrupo específico das exigibilidades, ambos discriminados nas Notas Explicativas.

As Notas Explicativas foram criadas com o objetivo de suprir as necessidades de informações que os usuários da Contabilidade detinham, pois as Demonstrações Financeiras apresentam apenas números, enquanto as Notas Explicativas apresentam as explicações para tais números e detalhamentos sobre as políticas da empresa, quais estratégias foram ou serão adotadas, seus registros, entre outros.

A pergunta que esta pesquisa busca responder é: Quais são as informações ambientais contábeis encontradas nas Notas Explicativas de empresas petroleiras e siderúrgicas de capital aberto?

O objetivo deste trabalho consiste em analisar quais são as informações ambientais contábeis contidas nas Notas Explicativas do conjunto de companhias abertas da área siderúrgica e petroleira, listadas na Bolsa de Valores, Mercadorias e Futuros de São Paulo - BM\&F Bovespa.

A justificativa de pesquisa do artigo é que não se tem registros de pesquisas anteriores que tratem especificamente do assunto da maneira aqui abordada feitas após a implementação das Leis $\mathrm{n}^{\circ} 11.941 / 09$ e $\mathrm{n}^{\mathrm{o}} 11.638 / 07$, que alteram alguns aspectos das Sociedades Anônimas, além dos novos pronunciamentos feitos pelo Comitê de Pronunciamentos Contábeis (CPC).

\section{FUNDAMENTAÇÃO TEÓRICA}

Este artigo está fundamentado em conceitos econômicos da Contabilidade Ambiental, conforme Seiffert (2008, p. 17)

\begin{abstract}
A constatação de existência de limites ambientais ao crescimento econômico vem levando a uma preocupação com a elaboração de políticas que permitam a conciliação da atividade econômica com a proteção ambiental, ainda que em um primeiro momento pareça inviável conciliar essa dualidade.
\end{abstract}

Carvalho (2008) segue nessa mesma linha de raciocínio, mas retrata a preocupação com os funcionários e trata dessa questão como indicadores sociais internos, que, junto com os externos, podem ampliar o sentido de cidadania.

Para Tinoco e Kraemer (2004), a Contabilidade Ambiental destaca os gastos ambientais decorrentes das atividades operacionais das empresas em razão da preocupação com o meio ambiente, abordando os eventos ambientais do processo produtivo, bem como as medidas preventivas que contribuam para a criação da imagem perante a opinião pública.

De acordo com Paiva (2003), todos os gastos e provisões efetuados para o meio ambiente devem ser evidenciados e para que isso seja feito de maneira mais explícita "[...] as demonstrações contábeis devem ser complementadas por notas explicativas, quadros analíticos ou outras demonstrações contábeis necessárias à plena avaliação da situação e da evolução patrimonial da empresa" (Iudicibus et al., 2010).

Segundo Ribeiro (2010), evidenciar implica questionar termos como "o quê": todas as informações relativas aos eventos; "como": com o grau de detalhamento exigido pela relevância dos 
valores; "quando": o registro contábil poderá ser feito no devido momento; "onde": idealmente, no corpo das Demonstrações Contábeis e nas Notas Explicativas. E nesse ponto Ribeiro (2010) converge com Pfitscher (2004) em seu "5W2H", que implica perguntar: what? (o quê); why? (por quê); when? (quando?), where? (onde?); who? (quem?); how? (como?) e, por fim, how much? (quanto custa?), perguntas estas que complementam as Notas Explicativas. É importante salientar que, para Campos e Lerípio (2009), existe também a necessidade de se fazer uma auditoria ambiental, que tem como motivos desenvolver uma política ambiental corporativa, buscar conformidade legal, aumentar a competitividade, estimar os riscos e as responsabilidades, entre outros motivos que seriam importantes para fins de evidenciação.

As Demonstrações Contábeis surgiram da necessidade de o gestor da atividade econômica controlar, avaliar e analisar a situação patrimonial da entidade (ativos, passivos e patrimônio líquido). Com a expansão das empresas, novos cenários econômicos foram se criando, como o da responsabilidade social. A partir desse conhecimento, entendendo que o lucro é um meio e não um fim, a empresa deveria coadunar os interesses do seu diversificado público a fim de atender suas expectativas, seja em termos de abastecimento do mercado ou de preservação do meio ambiente. (Ribeiro, 2010).

Atualmente, as informações de natureza ambiental contidas em relatórios contábeis são descritivas, limitando-se, na maioria dos casos, a mencionar que a empresa investiu na preservação do meio ambiente, não mencionando montantes e nem se os gastos foram registrados como ativos ou passivos ambientais. (Ribeiro, 2010).

Segundo a Lei ${ }^{\circ}$ 6.404/76 e suas alterações posteriores, todas as entidades devem, ao final de seu exercício social, exibir as seguintes demonstrações contábeis: Balanço Patrimonial; Demonstração de Lucros ou Prejuízos Acumulados; Demonstração do Resultado do Exercício; Demonstração do Fluxo de Caixa; Demonstração do Valor Adicionado, em caso de companhia aberta (BRASIL, 1976).

Tais demonstrações devem ser complementadas por Notas Explicativas que contenham a descrição dos critérios de avaliação dos elementos patrimoniais e das práticas contábeis adotadas, dos ajustes dos exercícios anteriores, das reavaliações e outras complementações. "Portanto notas explicativas são informações complementares às demonstrações contábeis, sendo parte integrante das mesmas". (Iudicibus et al., 2010).

Iudicibus et al., (2010, p. 591) afirmam que "[...] as notas explicativas podem ser usadas para descrever práticas contábeis utilizadas pela companhia, para explicações adicionais sobre determinadas contas ou operações específicas e ainda para composição e detalhes de certas contas.”

A Lei n 6.404/76 impele algumas normas quanto à apresentação das Notas Explicativas, tais como apresentar informações sobre a base da preparação das demonstrações contábeis específicas, selecionadas e aplicadas para negócios e eventos significativos; divulgar as informações exigidas pelas práticas contábeis adotadas no Brasil; fornecer informações adicionais não indicadas nas próprias demonstrações financeiras; indicar as taxas de juros, datas de vencimento e garantias das obrigações a longo prazo, entre outros.

Existe uma extensa gama de informações que deve constar em Notas Explicativas e que precisam, portanto, ser cuidadosamente analisadas, por ocasião da elaboração das demonstrações contábeis, tendo por base os pronunciamentos emitidos pelo Comitê de Pronunciamentos Contábeis (CPC). Para tanto, é necessário verificar que tipos de informação devem constar nessas notas e não se restringir apenas aos requisitos mínimos da Lei $\mathrm{n}^{\circ}$ 6.404/76.

Segundo as informações de Cunha, Ebsen e Limongi (2010) referentes à água e ao saneamento básico, pode-se notar que as informações ambientais contidas em Notas Explicativas se referem a terrenos para preservação ambiental, investimentos em preservação, ações judiciais que preveem supostos danos ambientais, entre outros. Apesar de não serem obrigatórias ainda, tais informações são de grande valia, pois é necessário saber como tais empresas cuidam do ambiente em que estão inseridas e como é sua relação com os stakeholders.

Revista de Gestão Social e Ambiental - RGSA, São Paulo, v. 6, n. 3, p. 183-195, set./dez. 2012. 
Essa divulgação de informações ambientais para esclarecer as operações da empresa diante de seus clientes pode ser notada no setor petrolífero, principalmente na empresa Petrobras (2010), que divulga a situação atual dos impactos ambientais que ela causou e as medidas que estão sendo encaminhadas.

No Brasil, o parque siderúrgico nacional começou a se constituir no início do século XX, por meio de investimentos privados e com baixas taxas de crescimento, recuperadas apenas no século XXI. Na verdade, somente ganhou consistência após a entrada de investimentos do poder público e com a criação de empresas estatais na década de 1940. Entretanto, com o passar dos anos, o Estado perdeu sua capacidade de investimento e também de manutenção das empresas. Foi a partir dessa situação que, no início dos anos de 1990, o setor passou por diversas reformulações, como privatizações e aquisições por estrangeiros.

Pode-se dizer que os principais fatos que levaram os países a privatizarem suas siderúrgicas foram: a) a perda do caráter estratégico do aço como insumo básico; b) a necessidade de se livrarem de uma fonte consumidora de recursos escassos; c) a maior facilidade de alienação de siderúrgicas, em comparação com as empresas de serviços públicos.

As indústrias siderúrgicas, por retirarem recursos da natureza, devem ter cuidado com aquilo que lhe é devolvido. Mas, devido à forte produção nesse meio, os gastos com energia elétrica são enormes; à medida que esse consumo for menor, a sua necessidade de produção também será menor. Outro fator importante para a preservação do meio ambiente é a substituição do carvão mineral pelo vegetal, que é menos nocivo ao meio ambiente.

Em 1938, a discussão sobre o uso e a exploração dos recursos do subsolo brasileiro viabilizou a criação do Conselho Nacional do Petróleo (CNP). Em suas primeiras ações, o Conselho determinou várias diretrizes a respeito do petróleo e estabeleceu que as jazidas pertencessem à União. No ano seguinte, o primeiro poço de petróleo foi encontrado.

Logo em seguida, novas prospecções governamentais saíram em busca de outros campos de petróleo ao longo do território brasileiro. No ano de 1941, o governo brasileiro anunciou o estabelecimento do campo de exploração petrolífera de Candeias, Bahia. Apesar das descobertas em pequena escala, o surgimento dessa nova riqueza incentivou, em 1953, a oficialização do monopólio estatal sobre a atividade petrolífera e a criação da empresa estatal "Petróleo Brasileiro S.A.", mais conhecida como Petrobras.

Após a Revolução Industrial Inglesa, houve a adoção do carvão como fonte de energia, principalmente por sua relativa abundância, pelo baixo preço, pela facilidade de extração, pelo transporte e pela sua conversão em combustível. No entanto, após a descoberta do petróleo e seu potencial energético, ele e seus derivados tornaram-se a forma mais importante de energia já encontrada pelo homem, a tal ponto que a sua abundância ou escassez geraram crises econômicas de repercussão mundial. (Lins, 2004).

O setor petrolífero tem um alto potencial poluidor, principalmente devido ao seu transporte em navios, uma vez que o seu vazamento nos oceanos pode provocar uma série de impactos, entre eles alterações físicas e químicas dos habitats naturais como, por exemplo, recobrimento físico da fauna e da flora, além de efeitos letais e subletais nos organismos. (Silva, 2004).

No Brasil, a Lei no 9.478/97, conhecida como a "lei do petróleo", dispõe sobre a política energética nacional e as atividades relativas ao monopólio do petróleo, além de instituir o Conselho Nacional de Política Energética e a Agência Nacional do Petróleo e dar outras providências.

A Agência Nacional de Petróleo (ANP), instituída pela Lei no 9.478/97, tem a função de ser o órgão regulador da indústria de petróleo, do gás natural, de seus derivados e dos biocombustíveis. Vinculada ao Ministério de Minas e Energia, ela colabora para a atração de investimentos, o aperfeiçoamento tecnológico e a capacitação de recursos humanos da indústria.

O Conselho Nacional de Política Energética (CNPE) tem a função de formular políticas e diretrizes de energia destinadas à preservação do interesse nacional, à proteção do meio ambiente e à promoção da conservação de energia, à atração de investimento na produção de energia, entre outros. 
A Lei $n^{\circ}$ 9.478/97 também dispõe informações sobre a Petrobras, afirmando que ela é uma sociedade de economia mista, vinculada ao Ministério de Minas e Energia, que tem como objetivo a lavra, o refino, o processamento, o comércio e o transporte de petróleo.

\section{MÉTODO DE PESQUISA}

Quanto ao seu objetivo, esta pesquisa se classifica como exploratória e descritiva, pois visa, primeiramente, explorar os dados apresentados nas Notas Explicativas e, posteriormente, descrevêlos sob forma analítica.

Quanto à abordagem dos dados, ela é classificada como qualitativa. Segundo Richardson e Peres (1999), a pesquisa de caráter qualitativo não tem a pretensão de enumerar ou medir unidades e não emprega instrumentos estatísticos como análise de resultados.

Quanto ao procedimento técnico, ela se enquadra como pesquisa documental e bibliográfica, pois as Notas Explicativas se enquadram como documentos presentes nas Demonstrações Contábeis. De acordo com Gil (2010), a pesquisa documental apresenta muitas semelhanças com a pesquisa bibliográfica, mas a documental vale-se de qualquer documento e tem várias finalidades.

A trajetória metodológica deste trabalho foi constituída de três etapas. A primeira consistiu em levantar os dados sobre os conceitos que seriam utilizados ao longo do trabalho, tais como Contabilidade Ambiental e Companhias Abertas do Ramo da Siderurgia e Petróleo.

$\mathrm{Na}$ segunda etapa foram feitas as coletas das Notas Explicativas referentes aos exercícios de 2007, 2008 e 2009 das seguintes empresas: Companhia de Ferros Ligas da Bahia - FERBASA (2010); Companhia Siderúrgica Nacional - CSN; Gerdau S.A(2010) e Usinas Siderúrgicas de Minas Gerais S.A., Indústria Brasil Ecodiesel (2010), Manguinhos (2010), OGX Petróleo e Gás e Petrobras (2010). Tais informações foram encontradas nos sítios eletrônicos das respectivas companhias e da BM\&F Bovespa (2010).

$\mathrm{Na}$ terceira etapa foram feitas buscas no Microsoft Word® pelas referências relacionadas aos termos "meio ambiente", "ambiental", "ambientais". Os termos e parágrafos que mencionavam esses conceitos foram listados para análise posterior. Foi feita, então, a análise das informações contidas nesses parágrafos e identificada a espécie de cada informação mencionada.

Para este trabalho, a Metalúrgica Gerdau S.A. e a Aços Villares S.A. não farão parte da pesquisa com seus respectivos nomes, tendo em vista que compõem a amostra das Demonstrações Contábeis da Gerdau S.A. como controladas. Por fim, a Vicunha Siderurgia S.A. não irá compor a amostra analisada, por se tratar de uma empresa de participação em outras sociedades, portanto, não atua diretamente no ramo siderúrgico.

\section{ANÁLISE DAS NOTAS EXPLICATIVA}

A análise das Notas Explicativas acerca desse tema teve como foco as Demonstrações Contábeis Obrigatórias de quatro companhias de capital aberto com ações listadas na BM\&F Bovespa que fazem parte do setor de siderurgia e petróleo.

\subsection{Análise dos dados - Metalúrgica Gerdau e Gerdau S/A}

Foram analisadas as Notas Explicativas da Gerdau que constavam nas Demonstrações Financeiras Obrigatórias dos anos de 2007, 2008 e 2009 e nelas não foram encontradas referências acerca do tema ambiental, especificamente.

Mas nas DFCs de 2007, a empresa indicou que toma cuidados com o meio ambiente e os gastos relacionados ao atendimento a regulamentos ambientais são considerados como "custos de produção", enquanto as áreas impactadas pela indústria de siderurgia são registradas na conta de "Outras contas a pagar no longo prazo". 14,96\% dessa conta representam o valor de R\$56.796, o qual está dividido em $\mathrm{R} \$ 29.282$ para as subsidiárias brasileiras e $\mathrm{R} \$ 27.514$ para as subsidiárias

Revista de Gestão Social e Ambiental - RGSA, São Paulo, v. 6, n. 3, p. 183-195, set./dez. 2012. 
norte-americanas. A empresa entende que está de acordo com as normas ambientais atualmente em vigor. Relata também a destinação, durante o exercício social, de $\mathrm{R} \$ 345,7$ milhões para a área, o que representa uma evolução de 105,1\% em 2006. Possui certificação da ISO 14001, que se refere ao tema ambiental, em 23 de suas unidades.

Ademais, a Gerdau informa que prioriza a contratação de fornecedores que também priorizem a questão ambiental, além de registrar provisões para eventuais passivos ambientais com base nas melhores estimativas de custos potenciais de limpeza e de reparação em locais conhecidos. Para reduzir seus custos, utiliza materiais reciclados e/ou materiais para serem reciclados na siderurgia.

Nas DFCs de 2008, a Gerdau apresentou informações já constantes nos anos anteriores sobre sua política de preservação do meio ambiente. No que tange ao registro dos gastos com atendimentos a regulamentos ambientais, estes ainda são considerados como "custo de produção". As áreas impactadas pela siderurgia são registradas na conta "outras contas a pagar no longo prazo", que teve seu saldo atualizado para $\mathrm{R} \$ 92.755$, o que representa $22,3 \%$ do total da conta. Destes, $\mathrm{R} \$ 28.896$ são destinados para as subsidiárias brasileiras e $\mathrm{R} \$ 63.859$ para as subsidiárias norteamericanas. Em 2008, R \$201 milhões foram destinados a práticas de proteção ambiental. Quanto às certificações da ISO 14001, estas passaram de 23 para 41 plantas em todo o mundo, sendo que o objetivo é certificar todas até 2012. A empresa também mantém o registro das provisões para eventuais passivos ambientais.

A Gerdau segue a mesma linha nas DFCs de 2009, mas não relata sobre a atualização do registro de novos valores na conta "outras contas a pagar no longo prazo", como vinha fazendo. Relata, porém, sobre os investimentos em práticas de proteção ambiental, que somam $\mathrm{R} \$ 173,2$ milhões.

\subsection{Análise dos dados - Companhia Siderúrgica Nacional}

No caso da Companhia Siderúrgica Nacional (CSN, 2010), foram analisadas as Notas Explicativas de 2007, 2008 e 2009. Nas de 2007, foram encontradas informações a respeito do meio ambiente, tanto em sua missão quanto em seus valores, que pregam o respeito e a harmonia com o meio ambiente, além de informações ambientais referentes à provisão para ações ambientais, no valor de R\$55.202.

Nas NEs de 2008 foram encontradas informações a respeito da provisão para ações ambientais, no valor de $\mathrm{R} \$ 71.731$, além de relatos sobre a preocupação com passivos ambientais. Nas demais demonstrações, a empresa relatou que, em 2008, foram empregados $\mathrm{R} \$ 331$ milhões em meio ambiente, o que correspondeu a um aumento de $17 \%$ em relação ao ano anterior. Os investimentos de capital em meio ambiente naquele ano foram de $\mathrm{R} \$ 113,5$ milhões, ou seja, 19,4\% superior ao investimento em 2007 e $96 \%$ superior ao investimento de 2006. A empresa ostenta a certificação pela ISO 14001.

A CSN economiza $45 \%$ a mais de água e gera $89 \%$ a menos de efluentes em comparação com o período anterior, utilizando um sistema de lavação de latas. Ao longo de 2008, os trabalhos de investigação, análise e recuperação de passivos ambientais herdados pela companhia quando de sua privatização tiveram prosseguimento.

Em seu balanço, foram provisionados $\mathrm{R} \$ 71,361$ milhões para fazer frente a esses passivos, obrigações formalmente estabelecidas por meio de instrumento administrativo ou judicial, bem como riscos considerados prováveis, para os quais é possível realizar uma estimativa razoável de custos com remediação, indenizações, sanções ou compensações pecuniárias. A CSN é adepta da reciclagem e, em 2008, a Usina Presidente Vargas gerou 3,38 milhões de toneladas de resíduos. Desse total, $73,8 \%$ foram vendidos; $24,39 \%$ foram reciclados internamente; $0,15 \%$, reciclados externamente; $0,13 \%$ coprocessados em fornos de cimento, internamente; $0,1 \%$ incinerados e apenas $1,43 \%$ foram dispostos em aterros licenciados para receber tais resíduos.

Revista de Gestão Social e Ambiental - RGSA, São Paulo, v. 6, n. 3, p. 183-195, set./dez. 2012. 
Nas NEs de 2009, a empresa manteve a mesma linha, evidenciando as suas informações ambientais, atualizando o valor da sua provisão para $\mathrm{R} \$ 116.309$ e retratando sua intenção de registrar seus passivos ambientais na aplicação em gastos relativos a serviços para investigação e recuperação ambiental de áreas com potencial de contaminação em estabelecimentos da companhia nos estados do Rio de Janeiro, Minas Gerais e Santa Catarina. As provisões para passivos cíveis, trabalhistas, fiscais, ambientais e previdenciários foram estimadas pela Administração, consubstanciadas significativamente na avaliação de assessores jurídicos, havendo sido registradas apenas as causas que se classificam como risco de perda provável.

\subsection{Análise dos dados - Usiminas}

$\mathrm{Na}$ Usiminas, foram analisadas as informações das Notas Explicativas de 2007, 2008 e 2009. Desde o início de suas Demonstrações Contábeis de 2007, a empresa já mencionava o respeito e a preocupação com o meio ambiente e o controle ambiental, mas relatava que sua controlada Cosipa havia recebido notificação fiscal relativa ao financiamento dos benefícios concedidos, em razão do grau de incidência de incapacidade laborativa decorrente dos riscos ambientais. Nas DFCs, mencionava que os gastos com a recuperação ambiental eram registrados como parte dos custos dos respectivos ativos, em contrapartida à provisão que suportaria tais gastos, além de levar em conta as estimativas da administração da companhia de futuros gastos trazidos para o valor presente. Na Usina José Bonifácio de Andrada e Silva, em Cubatão (SP), os investimentos em equipamentos para controle dos impactos ambientais somaram $\mathrm{R} \$ 33,13$ milhões em 2007, sendo R \$92.012 o total de todo o Grupo Usiminas. Ademais, a empresa cumpriu de 76\% a $100 \%$ as metas para minimizar resíduos despejados na natureza, de acordo com seu Balanço Social.

Nas NEs de 2008, a empresa demonstrava que uma usina nova passaria a operar estando atenta aos cuidados com o meio ambiente. Ainda relatava a notificação fiscal recebida pela sua controlada relativa ao financiamento dos benefícios concedidos, destinados ao financiamento das aposentadorias especiais, em razão do grau de incidência de incapacidade laborativa decorrente dos riscos ambientais. Demonstrava também duas provisões para despoluição da Baía de Sepetiba $(\mathrm{R} \$ 32.800)$ e de áreas em exploração ( $\mathrm{R} \$ 44.000)$. Já nas DFCs, o total dos investimentos no meio ambiente chegava a $\mathrm{R} \$ 269.975$. Os gastos com a recuperação ambiental foram registrados como parte dos custos dos respectivos ativos em contrapartida à provisão que suportaria tais gastos. Foram levadas em conta as estimativas da administração da companhia de futuros gastos trazidos ao valor presente. Em 2008, ela possuía provisão para recuperação ambiental da Baía de Sepetiba, que compreendia sua despoluição, no valor de $\mathrm{R} \$ 32.800$, e recuperação de áreas em exploração, no valor de $\mathrm{R} \$ 44.000$. Cumpre salientar que a empresa também foi certificada pela ISO 14001.

Em suas NEs de 2009, a Usiminas relatava que os gastos ambientais faziam parte do custo de seus respectivos ativos em contrapartida à sua provisão. Sua conta "obras em andamento" continha valores referentes a obras para melhoria ambiental e mantinha planos para atualização tecnológica e de proteção ambiental para 2011. Nas DFCs, dizia haver iniciado o trabalho de descontaminação do terreno na Baía de Sepetiba, no qual seria instalado seu porto próprio em Itaguaí (RJ). Considerado o maior passivo ambiental assumido pela companhia, a área adquirida de uma empresa de mineração em 2008 contém um lago contaminado por efluentes líquidos. $\mathrm{O}$ custo total da recuperação será de $\mathrm{R} \$ 40$ milhões e a descontaminação deve durar de 15 a 18 meses. A Usiminas relatava, ainda, o valor total de multas ambientais pagas por ela em 2009, no valor de $\mathrm{R} \$ 148.839$, enquanto os investimentos nessa área foram de $\mathrm{R} \$ 590$ milhões.

\subsection{Análise dos dados - FERBASA}

Revista de Gestão Social e Ambiental - RGSA, São Paulo, v. 6, n. 3, p. 183-195, set./dez. 2012. 
Nas Notas Explicativas da Companhia de Ferro Ligas da Bahia - Ferbasa e controladas foram analisadas as NEs de 2007, 2008 e 2009. Assim, nas NEs de 2007, a empresa relatava a preocupação com o meio ambiente e com a elaboração de seus projetos para não afetá-los. Porém, o IBAMA lhe aplicou um auto de infração no montante de R\$ 691 mil para 31 de dezembro de 2007. Este auto de infração estava sendo defendido judicialmente e, baseava-se na opinião de seus assessores jurídicos. A administração manteve registrada a provisão para fazer atender as perdas, consideradas como prováveis, no referido montante.

Não havendo mudança na situação, as NEs de 2008 e 2009 da companhia mantiveram registrado o auto de infração no montante de $\mathrm{R} \$ 691$ mil para 31 de dezembro de 2008 e de 2009, e a provisão para fazer cobrir as perdas consideradas prováveis, no mesmo montante.

\subsection{Análise comparativa de empresas Siderúrgicas}

Por meio de comparações entre as quatro empresas, é possível perceber que as informações ambientais apresentadas foram mais satisfatórias e evidentes em algumas das entidades, como pode ser observado na figura 1 :

\begin{tabular}{|l|c|c|c|c|}
\hline \multicolumn{1}{|c|}{ Dados } & Gerdau & $\begin{array}{c}\text { Usimina } \\
\text { s }\end{array}$ & CSN & FERBASA \\
\hline $\begin{array}{l}\text { Gastos considerados como custo de } \\
\text { produção }\end{array}$ & $\mathrm{X}$ & $\mathrm{X}$ & & \\
\hline Provisões ambientais & $\mathrm{X}$ & & & \\
\hline Certificação pela ISO 14001 & $\mathrm{X}$ & $\mathrm{X}$ & & \\
\hline Questões judiciais & & & & $\mathrm{X}$ \\
\hline Auto de infração & $\mathrm{X}$ & $\mathrm{X}$ & $\mathrm{X}$ & \\
\hline $\begin{array}{l}\text { Destinação de verba para questões } \\
\text { ambientais }\end{array}$ & & & $\mathrm{X}$ \\
\hline
\end{tabular}

Figura 1 - Comparativo das empresas de 2007-2008-2009

Fonte: Elaborado pelos autores

Em termos qualitativos, foram detectadas as mesmas informações ambientais nas Notas Explicativas das empresas ao longo dos três exercícios sociais estudados. Como pode ser observado na figura 1, a Gerdau foi a empresa que evidenciou a maior quantidade de informações ambientais. A destinação de verbas para questões ambientais foi o tipo de informação mais encontrada, aparecendo nas notas de três das quatro empresas estudadas.

\subsection{Análise dos dados - Brasil Ecodiesel}

A Ecodiesel apresentou em suas Notas Explicativas, relativas ao ano de 2007, o valor de licenciamentos ambientais subdivididos em custo (20), amortização (4) e valor líquido (18). No ano de 2008, foi apresentado, em suas Notas Explicativas, um contrato de incentivo fiscal com vigência de 60 meses, denominado "Fundopem". O referido contrato possui cláusulas de execução relacionadas à regularidade de obrigações contratuais junto ao Banco do Estado do Rio Grande do Sul S/A, à Caixa Estadual S/A - Agência de Fomento/RS e ao Banco Regional de Desenvolvimento do Extremo Sul - BRDE, além de obrigações fiscais e ambientais decorrentes da legislação vigente e a geração de 168 novos postos de trabalho direto, ao longo de 8 (oito) anos. O saldo da parcela incentivada recolhida pelo ICMS em 2008 foi de R $\$ 2.453$. Em 2009, o mesmo contrato de incentivo fiscal foi apresentado nas Notas Explicativas, porém com o saldo líquido ajustado da parcela incentivada recolhida pelo ICMS no valor de $\mathrm{R} \$ 7.018$.

\subsection{Análise dos dados - Manguinhos - Refinaria de Petróleo}

Revista de Gestão Social e Ambiental - RGSA, São Paulo, v. 6, n. 3, p. 183-195, set./dez. 2012. 
A Manguinhos Refinaria de Petróleo apresentou, em suas Notas Explicativas relativas ao ano de 2007, um Termo de Ajustamento de Compromisso e Conduta Ambiental - TAC firmado entre a empresa, a Secretaria de Estado de Meio Ambiente (SAE) e a Fundação Estadual de Engenharia do Meio Ambiente (FEEMA), de maneira que 10\% do montante de R $\$ 3.033$ será aplicado em projetos de preservação e na melhoria e recuperação da qualidade do meio ambiente. As notas apresentam também a política que o Grupo adota no sentido de manter a cobertura de seguros para bens do Ativo Imobilizado, dos estoques sujeitos a riscos, dos lucros cessantes, tumultos e riscos ambientais.

No ano de 2008, o mesmo Termo de Ajustamento de Compromisso e Conduta Ambiental e sua política de seguros foram apresentados em suas Notas Explicativas, havendo apenas reajustes no valor líquido do saldo de "Instalações, equipamentos e estoques" de R $\$ 71.500$ para o valor de $\mathrm{R} \$ 50.813$ relativos aos seguros. Em 2009, novamente o TAC apresentou a conduta ambiental e a política de seguros, não havendo alterações nos valores líquidos dos últimos.

\subsection{Análise dos dados - OGX Petróleo e Gás Participações}

Não foi encontrada nenhuma referência relacionada aos termos "meio ambiente", "ambiental", "ambientais", "ecológico", "ecologia", "sustentável" e "sustentabilidade" nas Notas Explicativas da OGX referentes ao ano de 2007.

Já em 2008, a OGX apresentou, em suas Notas Explicativas, estudos de licenciamento e impactos ambientais sobre as atividades de fase exploratória relativas à perfuração de 29 poços.

No ano de 2009, novamente, parte dos gastos incorridos com a fase exploratória foi apresentada como estando diretamente relacionada a estudos de licenciamento e impactos ambientais.

\subsection{Análise dos dados - Petróleo Brasileiro S.A. - Petrobras}

No ano de 2007, foi apresentado nas Notas Explicativas da Petrobras o valor de gastos corporativos em "Segurança, meio ambiente e saúde" (SMS), na quantia de R\$ 474.520, além de uma cláusula específica relativa a questões ambientais na qual foi descrita a situação dos principais processos ambientais com perda possível. Tal cláusula apresentava a descrição dos processos ambientais e sua situação atual. Além dela, foi apresentada também outra cláusula, denominada "Segurança, meio ambiente e saúde" (SMS), que identificava o gasto total da Companhia com o meio ambiente no valor de $\mathrm{R} \$ 1.720 .000$ mil.

No Balanço Social contido nas Notas Explicativas daquele mesmo ano, foram apresentados Indicadores Ambientais divididos em: Investimentos relacionados com a produção/operação da empresa, no valor de $\mathrm{R} \$ 1.924 .698$ e Investimentos em programas e/ou projetos externos, no valor de $\mathrm{R} \$$ 51.728. Ainda no ano de 2007, as Notas informavam a promulgação da Lei $\mathrm{n}^{\mathrm{o}} 3.740$, de Desenvolvimento Sustentável do Setor de Hidrocarbonetos.

Em 2008, novamente foram apresentados os gastos corporativos em "Segurança, meio ambiente e saúde" (SMS), com alterações em seu valor para R\$382.170. Também foram apresentadas novamente as cláusulas próprias relativas a "Questões Ambientais", que não sofreram reajustes, e a cláusula denominada "Segurança, meio ambiente e saúde" que, por sua vez, sofreu alteração no seu valor para $\mathrm{R} \$ 1.715 .000$ mil, com gastos relativos ao meio ambiente.

Os Indicadores Ambientais contidos no Balanço Social de 2008 sofreram alterações em Investimentos relacionados à produção/operação da empresa no valor de $\mathrm{R} \$ 1.919 .751 \mathrm{e}$ em Investimentos em programas e/ou projetos externos no valor de $\mathrm{R} \$ 53.763$. Ainda no ano de 2008 , as Notas informaram a implantação da primeira usina comercial de produção de biodiesel, que, gerou emprego e renda, sem deixar de lado a sustentabilidade empresarial, social e ambiental.

A Petrobras, mais uma vez, apresentou, em suas Notas Explicativas relativas ao ano de 2009, suas cláusulas próprias referentes a questões ambientais, que, por sua vez, não sofreram

Revista de Gestão Social e Ambiental - RGSA, São Paulo, v. 6, n. 3, p. 183-195, set./dez. 2012. 
reajustes, e a cláusula denominada "Segurança, meio ambiente e saúde" que sofreu alteração no valor com gastos relativos ao meio ambiente para $\mathrm{R} \$ 1.875 .065$ mil.

Em 2009, os indicadores ambientais contidos no Balanço Social sofreram alterações em Investimentos relacionados com a produção/operação da empresa para $\mathrm{R} \$ 1.872 .458$, e em Investimentos em programas e/ou projetos externos para $\mathrm{R} \$ 151.626$.

\subsection{Análise comparativa de empresas petroleiras}

Depois de analisadas as empresas individualmente, procedeu-se a uma análise comparativa das Notas Explicativas. Na figura 2, são apresentadas as informações ambientais encontradas nas Notas Explicativas do ano de 2007 das empresas do setor petrolífero listadas na BM\&FBovespa.

\begin{tabular}{|l|c|c|c|c|}
\hline \multicolumn{1}{|c|}{2007} & Ecodiesel & Manguinhos & OGX & Petrobras \\
\hline Licenciamentos ambientais & $\mathrm{X}$ & & & \\
\hline Cláusulas contratuais & & & & \\
\hline Termos de ajustamento de conduta & & $\mathrm{X}$ & & \\
\hline Estudos de impactos ambientais & & & & \\
\hline Investimentos internos ambientais & & & & $\mathrm{X}$ \\
\hline Investimentos externos ambientais & & & & $\mathrm{X}$ \\
\hline Legislação pertinente & & & & $\mathrm{X}$ \\
\hline Seguros ambientais perdas & & & & $\mathrm{X}$ \\
\hline $\begin{array}{l}\text { Ações judiciais com } \\
\text { possíveis }\end{array}$ & & & & $\mathrm{X}$ \\
\hline Cálculos de provisões ambientais & & & & \\
\hline
\end{tabular}

Figura 2 - Comparativo das notas explicativas de 2007

Fonte: Elaborado pelos autores

Pode-se observar, por meio do quadro comparativo e das Notas Explicativas referentes ao ano de 2007, que a Ecodiesel foi à empresa que apresentou licenciamentos ambientais em suas atividades, sendo que tal informação foi a única relativa à Contabilidade Ambiental no ano de 2007.

A empresa Manguinhos apresentou um Termo de Ajustamento de Compromisso (TAC) relacionado à Conduta Ambiental, em que consta que irá investir uma porcentagem de seus investimentos em projetos de preservação e melhoria do meio ambiente. Além deste Termo, a empresa apresentou informações sobre sua política de seguros com relação a riscos ambientais.

Em 2007, a empresa OGX não apresentou nenhuma informação referente a "meio ambiente", "ambiental", "ambientais", "ecológico", "ecologia", "sustentabilidade" e "sustentável", como se pode notar em suas Notas Explicativas e na figura comparativa acima.

A empresa Petrobras apresentou informações quanto ao valor de investimentos feitos em programas e/ou projetos externos e investimentos relacionados com a produção da empresa referentes ao meio ambiente. Além de tais investimentos, a empresa informou sobre a promulgação da Lei no 3.740, de Desenvolvimento Sustentável do Setor de Hidrocarbonetos. Também nas Notas Explicativas e na figura comparativa foram apresentadas informações quanto a Ações Judiciais relacionadas ao meio ambiente, que descrevem tais ações e mostram a situação atual de cada uma, calculando, para cada ação, uma provisão para perdas possíveis relativas ao ano de 2007.

Nota-se, por meio da figura comparativa, que não há uma padronização com relação à apresentação de dados referentes ao meio ambiente. Percebe-se que a Petróleo Brasileiro - Petrobras é a empresa que mais apresenta informações relativas ao meio ambiente e que, por sua vez, a OGX foi à única empresa que não apresentou informações quanto ao meio ambiente em 2007. Na figura 3, são apresentadas as informações ambientais encontradas nas Notas Explicativas dos anos de 2008 
e 2009, visto que em ambos as informações fornecidas pelas empresas do setor petrolífero listadas na BM\&FBovespa se repetem.

\begin{tabular}{|l|c|c|c|c|}
\hline \multicolumn{1}{|c|}{ 2008/2009 } & Ecodiesel & Manguinhos & OGX & Petrobras \\
\hline Licenciamentos ambientais & & & & \\
\hline Cláusulas contratuais & $\mathrm{X}$ & & & \\
\hline Termos de ajustamento de conduta & & $\mathrm{X}$ & & \\
\hline Estudos de impactos ambientais & & & $\mathrm{X}$ & \\
\hline Investimentos internos ambientais & & & & $\mathrm{X}$ \\
\hline Investimentos externos ambientais & & & & $\mathrm{X}$ \\
\hline Legislação pertinente & & & & $\mathrm{X}$ \\
\hline Seguros ambientais & & $\mathrm{X}$ & & $\mathrm{X}$ \\
\hline Ações judiciais com perdas possíveis & & & & \\
\hline Cálculos de provisões ambientais & & & & \\
\hline
\end{tabular}

Figura 3 - Comparativo das notas explicativas de 2008 e 2009

Fonte: Elaborado pelos autores

Pode-se observar, na figura comparativa e das Notas Explicativas referentes aos anos de 2008 e 2009, que a Ecodiesel foi a única empresa que apresentou cláusulas contratuais em suas Notas Explicativas relativas a um incentivo fiscal denominado "Fundopem", referente a obrigações fiscais e ambientais decorrentes da legislação vigente; tal cláusula contratual foi a única informação relativa ao meio ambiente apresentada pela empresa.

A empresa Manguinhos apresentou novamente um Termo de Ajustamento de Compromisso (TAC) relacionado à conduta ambiental, segundo o qual irá investir uma porcentagem de seus investimentos em projetos de preservação e de melhoria do meio ambiente. Além do Termo de Ajustamento de Compromisso, a empresa reapresentou informações sobre sua política de seguros com relação a riscos ambientais referentes aos anos de 2008 e 2009.

Em 2008 e 2009, a empresa OGX apresentou apenas uma informação quanto ao meio ambiente, como se pode notar em suas Notas Explicativas e na figura comparativa. Tal informação é referente aos gastos incorridos com a fase exploratória, estando diretamente relacionada com estudos de licenciamento e impactos ambientais.

A empresa Petrobras reapresentou informações quanto ao valor de Investimentos feitos em programas e/ou projetos externos e Investimentos relacionados com a produção da empresa referentes ao meio ambiente. Além de tais investimentos, a Empresa novamente apresentou, em suas Notas Explicativas, ações judiciais relacionadas ao meio ambiente, descrevendo tais ações e mostrando a situação atual de cada uma, também recalculando, para cada ação, uma provisão para perdas possíveis relativas aos anos de 2008 e 2009.

\section{CONSIDERAÇÕES FINAIS}

Pelas leis vigentes, segundo as quais informações em Relatórios Contábeis não são obrigatórias, mas possuem um valor intangível para a imagem da empresa, também é importante saber a relação das companhias com os seus stakeholders. Entretanto, mesmo não sendo obrigatórias, todas as empresas mencionadas citaram termos acerca da questão ambiental. Algumas evidenciaram mais do que as outras, haja vista que são empresas do mesmo ramo, mas que apresentam tamanhos e perfis diferentes. É importante salientar que a Gerdau nada apresentou nas suas Notas Explicativas no que tange a sua Contabilidade Ambiental e a FERBASA, especificamente, embora tenha mostrado, de forma bastante sutil, informações ambientais em suas NEs. O fato de a empresa estar entre as 20 maiores do seu estado deveria fazer com que ela 
evidenciasse mais suas informações ambientais. Já as demais empresas apresentaram mais informações sobre o meio ambiente. Destas, o destaque coube para a Usiminas que destinou maior espaço ao assunto em suas Demonstrações Contábeis.

Já as informações ambientais encontradas nas Notas Explicativas das empresas do setor petrolífero se referem a investimentos ambientais, seguros ambientais e legislação ambiental, incluindo Termos de Ajustamento de Conduta e cláusulas contratuais firmadas por tais empresas.

Comparando as informações encontradas nesta pesquisa com as informações encontradas por Cunha, Ebsen e Limongi (2010), pode-se notar que em ambas foram mencionadas as ações judiciais decorrentes de danos causados ao meio ambiente, os cálculos de provisões relacionadas a ações judiciais em andamento, e as cláusulas de contratos firmados pelas empresas. As informações divergentes entre as pesquisas são as relacionadas a seguros ambientais, que foram apresentados nesta pesquisa, e a posse de ativos ambientais, como terrenos e florestas, que foi apresentada por Cunha, Ebsen e Limongi (2010).

Nota-se, por meio desta pesquisa, que as empresas do setor petrolífero não possuem um padrão para apresentar informações ambientais em seus relatórios sociais, apesar dessas informações serem de grande valia para uma melhor visão sistêmica de como a empresa influi no meio ambiente. A Petrobras foi a empresa que apresentou uma melhor evidenciação de informações ambientais nas Notas Explicativas, encontradas principalmente no capítulo "Segurança, saúde e meio ambiente".

Sugere-se, para pesquisas futuras, uma abordagem desse tema também em empresas de outros setores, para que seja possível verificar se tais empresas estão à frente das que aqui foram analisadas, bem como ampliar o prazo das demonstrações analisadas, observando se há aumento ou redução da evidenciação das informações. Vale também pesquisar os Relatórios de Administração, tendo em vista que eles fazem parte das Demonstrações Financeiras e podem conter informações relevantes acerca do objeto estudado.

\section{REFERÊNCIAS}

BMF Bovespa. Bolsa de Valores Mercadorias e Futuros de São Paulo. (2010). Ações: Empresas Listadas. Recuperado em 30 de agosto, 2010, de <http://www.bmfbovespa.com.br/ciaslistadas/empresas-listadas/BuscaEmpresaListada.aspx?Idioma=pt-br>.

Brasil. Lei 6.404/76: Dispõe sobre as Sociedades por ações. (2010). Compilada com a Lei 11.638/07 e 11.949/09. Recuperada em 30 de agosto, 2010, de <http://www.planalto.gov.br/ccivil_03/Leis/L6404compilada.htm>.

Campos, L. M. S. \& Lerípio, A. A. (2009). Auditoria ambiental: uma ferramenta de gestão. São Paulo: Atlas

FERBASA. Companhia de Ferros Ligas da Bahia. (2010). Pesquisa geral no site. Recuperado em 30 de agosto, 2010, de <http://www.ferbasa.com.br>.

CSN. Companhia Siderúrgica Nacional. (2010). Pesquisa Geral no site. Recuperado em 30 de agosto, 2010 ,

de <http://www.csn.com.br/portal/page?_pageid=456,170749\&_dad=portal\&_schema=PORTAL>.

Cunha, A. M., Ebsen, K. S., Limongi, B. (2010). Contabilidade ambiental e demonstrações financeiras obrigatórias: informações ambientais relevantes nas notas explicativas. In: Seminários em Administração, 13, São Paulo. Anais... São Paulo: USP. 
Ecodiesel, Brasil Ecodiesel. (2010). Perfil Corporativo e Histórico. Recuperado em 30 de agosto, 2010 ,

http://www.brasilecodiesel.com.br/brasilecodiesel/web/default_pti.asp?idioma=0\&conta=45

Gerdau S.A. (2010). Pesquisa geral no site. Recuperado em 30 de agosto, 2010, de <http://www.gerdau.com.br/>.

Gil, A. C. (2010). Como elaborar projetos de pesquisa. São Paulo: Atlas Iudicibus, S. et al., (2010). Manual de contabilidade societária: aplicável às demais sociedades. São Paulo: Atlas.

Lins, C. M. D. (2004). Evolução e influência do petróleo na economia brasileira. Monografia (Bacharelado) - Faculdades Integradas Antônio Eufrásio de Toledo.

Manguinhos. Manguinhos Refinaria de Petróleos. (2010). História. Recuperado em 25 de agosto, 2010, de <http://www.manguinhosrefinaria.com.br/conteudo/historia.php>.

Marion, J. C. (2009). Contabilidade empresarial. São Paulo: Atlas.

OGX. (2010). Histórico. Recuperado em: 25 ago.2010, de: <http://www.ogx.com.br/cgi/cgilua.exe/sys/start.htm?sid=23\&lng=br>.

Paiva, P. R. (2003). Contabilidade ambiental: evidenciação dos gastos ambientais com transparência e focada na prevenção. São Paulo: Atlas.

Petrobras. Petróleo Brasileiro S.A. (2010). Nossa História. Recuperado em 25 de agosto, 2010, de <http://www.petrobras.com.br/pt/quem-somos/nossa-historia/>.

Pfitscher, E. D. (2008). Gestão e sustentabilidade através da contabilidade e controladoria ambiental : estudo de caso na cadeia produtiva de arroz ecológico. . Dissertação de Doutorado UFSC, Florianópolis.

Ribeiro, M. S. (2010). Contabilidade ambiental. São Paulo: Saraiva.

Richardson, R. J. \& Peres, J. A. S. (1999). Pesquisa social: metodos e tecnicas. São Paulo: Atlas.

Seiffert, M. E. B. (2008). Sistemas de gestão ambiental (ISO 14001) e saúde e segurança ocupacional (OHSAS 18001): vantagens da implantação integrada. São Paulo: Atlas.

Silva, P. R.(2004). Transporte marítimo de petróleo e derivados na costa brasileira: estrutura e implicações ambientais. Tese (Mestrado) - Faculdades Integradas Antônio Eufrásio de Toledo.

Tinoco, J. E. P. \& Kraemer, M. E. P. (2004). Contabilidade e gestão ambiental. São Paulo: Atlas.

Usiminas. Usinas Siderúrgicas de Minas Gerais S.A. (2010). Pesquisa Geral no site. Recuperado em 30 de agosto, 2010, de <http://www.usiminas.com/irj/portal>.

Recebido em: 14/09/2011

Publicado em: 21/12/2012 